\title{
A Descriptive Study on Alleged Sexual Offenders in South Bangalore
}

\author{
Sujatha P. L ${ }^{1}$, Ananda. K ${ }^{2}$, Mandar Ramchandra Sane ${ }^{3}$ \\ ${ }^{1}$ Assistant Professor, ${ }^{2}$ Professor \& HOD, Department of Forensic Medicine Sambhram Institute of Medical \\ Sciences and Research, D.K. Plantation, BEML Nagar, Kolar Gold Fields, Karnataka, ${ }^{3}$ Assistant Professor, \\ Department of Forensic Medicine and Toxicology, AIIMS, Nagpur, Maharastra
}

\begin{abstract}
Rape is a serious offence and understanding the offender may help us to understand the antecedents leading (directly or indirectly) to the act. The examination of the survivors of alleged sexual offences is one of the most difficult tasks in Medical practice. Methodology: This study was carried out between January 2012 to June 2013 in the Department of Forensic Medicine at Tertiary care centre, South Bangalore, Karnataka. The cases registered under sections 375, 376 IPC and Protection of Children from Sexual Offences Act were included in the study. Results: Total 38 accused were examined during study period. $55.3 \%$ of cases were in the age group of 21 years to 30 years. $57.9 \%$ of cases were graduated, and $34.2 \%$ were employed. $44.7 \%$ cases belong to lower middle class (III). In $47.5 \%$ of cases the incident occurred between evening $\&$ mid night time. Offender was close friends of the victim in $47.5 \%$ cases. Non genital external injuries were present in $5.3 \%$ of cases. Discussion: Young adult males were involved in majority of cases due to their immature mind set. Majority of the offenders were close friends of the victim, and were booked due to stringent provisions of POCSO Act. Consensual sexual activity between teenagers can be decriminalized.
\end{abstract}

Key words: Sexual offence, perpetrator, 375 IPC, POCSO Act, rape.

\section{Introduction}

Sexual violence is ubiquitous; it occurs in every culture, in all levels of society and in every country of the world. Data from country and local studies indicate that, in some parts of the world at least, one woman in every four has suffered an attempted or completed rape by an intimate partner during her lifetime.(1) Sexual violence takes place within a variety of settings, including the home, the workplace, schools and the community. There are various ways and forms in which sexual exploitation is practiced. The most perverted and degrading form is rape. Incidence of rape, particularly among young and adolescent girls is reported almost daily.

\section{Corresponding author:}

Dr. Sujatha P. L.

Assistant Professor, Department of Forensic Medicine and Toxicology, Sapthagiri Institute of Medical Sciences \& Research centre, No.15, Chikkasandra, Hesaraghatta Main Road, Bangalore 560090

Email: dr.sujata.pl@gmail.com, Mob:+919844116333
According to the data collected by NCRB, rape cases have increased from 24206 cases in 2011 to 38947 cases in 2016(2), however as against this conviction rate of sexual offenders remains low i.e. around $28 \%$ in 2014(3) to $36 \%$ in 2016(4). This is inspite of the amendments made in Indian Penal Code (IPC), Criminal Procedure Code (CrPC), Indian Evidence Act (IEA) and enactment of POCSO Act, 2012 which provides legal protection to children below 18 years.

There are many studies on profile of victims of sexual offence whereas studies on profile of accused are less. Considering the danger of allowing true offenders to go unpunished as well as injustice of wrong convictions, the task of the examining physician becomes even more important. So, present study was aimed to find out the profile of sexual offences in South Bangalore and to describe the characteristics of accused of sexual assaults.

\section{Materials and Method}

This was a prospective descriptive study, carried out for a period from January 2012 to June 2013 in 
the Department of Forensic Medicine at Tertiary care centre, South Bangalore, Karnataka State, India. Study was started after approval from Institutional Ethical Committee. The cases registered under sections 375, 376 IPC (inclusive of amendments) and Protection of Children from Sexual Offences Act (POCSO Act) were included in the study. Similarly, alleged sexual offence cases which later turned out to be false allegations were not included in study. Sexual offenders involved in offences against males were also not included. Informed written consent has been taken from the accused. A standardized proforma was filled in each case after detailed interviews with the investigating officials and alleged accused. The information regarding the age, socio-economic background, level of education, occupation, marital status, history of sexual offence as stated by the accused. During examination, general details of the accused' health, mental state, physical examination, injuries, examination of the genitalia, and laboratory findings, were recorded in proforma. The comparison was made between these findings and conclusions were drawn after comparing and discussing with similar type of the work carried out by other authors.

\section{Results}

Total 38 accused were examined during study period. Maximum numbers of accused i.e. 21 cases $(55.3 \%)$ were in the age group of 21 years to 30 years. (Table 1) Maximum number of accused i.e. 22 (57.9\%) cases were graduated. Maximum number of accused i.e. 13 cases $(34.2 \%)$ were employed. $17(44.7 \%)$ cases belong to Lower middle class (III).(Table 2) In majority of cases i.e. $18(47.5 \%)$ cases the incident occurred between evening \& mid night time, i.e. from 6.00PM to 12.00AM.(Table 3) Among 38 cases, 18 (47.5\%) cases, the offence was committed by close friends of the victim followed by $10(26.3 \%)$ case, the accused were neighbours of victims.(Table 4) 15 (39.5\%) cases occurred in the accused house, followed by $9(23.7 \%)$ cases occurred in the other indoor places like lodge, friend's house.(Table 5) In the present study non genital external injuries were present in 2 cases (5.3\%).(Table6)

Table 1: Age wise Distribution of accused of sexual offence cases

\begin{tabular}{|l|l|l|}
\hline Age (years) & Accused (number) & Percentage \\
\hline $0-10$ & 00 & 00.00 \\
\hline $11-20$ & 08 & 21.05 \\
\hline $21-30$ & 21 & 55.26 \\
\hline $31-40$ & 08 & 21.05 \\
\hline $40+$ & 01 & 2.63 \\
\hline TOTAL & 38 & 100 \\
\hline
\end{tabular}

Table 2: Distribution of accused according to socio economic class

\begin{tabular}{|l|l|l|}
\hline Socio Economic Class & Number & Percentage \\
\hline Upper class(I) & 02 & 5.3 \\
\hline Upper middle class(II) & 07 & 18.4 \\
\hline Lower middle class(III) & 17 & 44.7 \\
\hline Lower class(IV) & 12 & 31.6 \\
\hline Total & 38 & 100 \\
\hline
\end{tabular}


Medico-legal Update, July-September 2020, Vol.20, No. 3

Table 3: Distribution of cases according to time of incident

\begin{tabular}{|l|l|l|}
\hline Time of incidence & Number & Percentage \\
\hline $12.00 \mathrm{am}$ to $6.00 \mathrm{am}$ & 10 & 26.3 \\
\hline 6.00 am to $12.00 \mathrm{pm}$ & 04 & 10.5 \\
\hline $12.00 \mathrm{pm}$ to $6.00 \mathrm{pm}$ & 06 & 15.7 \\
\hline $6.00 \mathrm{pm}$ to $12.00 \mathrm{am}$ & 18 & 47.5 \\
\hline Total & 38 & 100 \\
\hline
\end{tabular}

Table 4: Distribution of sexual offence cases based on the relation between victim \& accused

\begin{tabular}{|l|l|l|}
\hline Relation between accused and victim & Number & Percentage \\
\hline Close friend & 18 & 47.5 \\
\hline Relative & 04 & 10.5 \\
\hline Neighbour & 10 & 26.3 \\
\hline Stranger & 02 & 05.2 \\
\hline College mate & 04 & 10.5 \\
\hline Total & 38 & 100 \\
\hline
\end{tabular}

Table 5: Distribution of Cases According to Place of Incident

\begin{tabular}{|l|l|l|}
\hline Place of incidence & Number & Percentage \\
\hline Victims' house & 08 & 21.0 \\
\hline Accused house & 15 & 39.5 \\
\hline Other indoor (lodge, friend's house) & 09 & 23.7 \\
\hline Outdoor & 06 & 15.8 \\
\hline Total & 38 & 100 \\
\hline
\end{tabular}

Table 6: Physical Findings in the Accused of sexual offence

\begin{tabular}{|l|l|l|}
\hline Findings & Number & Percentage \\
\hline Non-genital external injuries & 02 & $5.3 \%$ \\
\hline Local genital injuries & NIL & - \\
\hline Matted pubic hairs & NIL & - \\
\hline Loose hairs at genitalia & NIL & - \\
\hline Presence of smegma & 01 & $2.6 \%$ \\
\hline Penis circumcised & 05 & $13.2 \%$ \\
\hline Urethral discharge/ signs of sexually transmitted diseases & NIL & - \\
\hline
\end{tabular}




\section{Discussion}

Thirty eight cases of sexual assault were examined. Age of accused ranged from 17 to 57 years. Majority of the accused (55.26\%) were in the age group of 21 30 years. This finding is consistent with the findings of studies done by Bhowmik ${ }^{(5)}$ and Veeresh ${ }^{(6)}$. Offenders were of younger age group due to their immature mind set which make them prone to indulge in unlawful sexual activity.

Considering the education of accused, 22 cases $(57.9 \%)$ were graduates, $12(32 \%)$ cases were studied up to school and 4 cases $(10.5 \%)$ were illiterates. The findings in the present study differ from the study done by Veeresh $^{(6)}$ in which $77.28 \%$ of accused were illiterates. In our study maximum number of accused i.e. 13(34.2\%) were employed, followed by $12(31.6 \%)$ were labourer by occupation. The findings in this study differ from the study done by Veeresh ${ }^{(6)}$ in which $54.55 \%$ of accused were labourers. Considering the socio economic status of the accused, the present study shows that majority of accused i.e.17 (44.7\%) cases belong to Class III, followed by $12(31.6 \%)$ cases belong to Class IV. Least number of accused i.e. $2(5.3 \%)$ cases belongs to Class I. The findings of this study slightly differs from the other study done by Veeresh et $\mathrm{al}^{(6)}$ in which majority of the accused were from poor socio economic status.

Our study showed that majority of cases i.e. 18 (47.5\%) occurred between evening \& night time, i.e. from 6.00PM to 6.00 AM. These figures are similar to those encountered in studies in India ${ }^{(7)}$ and non-Indian community ${ }^{(8)}$. The reason attributed towards the highest incidents occurring at night are that during this period either the event takes place unnoticed or the victim cannot get help from others ${ }^{(7)}$ or due to social habits of the majority of victims and the fact that cover of darkness can give opportunities for assaults to take place ${ }^{(8)}$.

In the present study, majority of the sexual assault i.e. $15(39.5 \%)$ cases occurred in the accused house. It is followed by $9(23.7 \%)$ cases occurred in the other indoor places like lodge, friend's house. The findings of our study are consistent with the study done by Sean D McDermott et al ${ }^{(8)}$ in which $43 \%$ of cases occurred in the indoors but he has not categorized as victims'/ accused house. It differs from study by Roychowdhury et al ${ }^{(9)}$ who observed in $77.5 \%$ of cases the incidence occurred outside, and, it also differs from the study done in Bangladesh $^{(10)}$ in which $36.95 \%$ of incidents occurred in victims' house. The occurrence of events mostly inside the house is attributed to the accused being able to trap the victim easily inside a closed room ${ }^{(7)}$.

Relationship of accused with the victim has been studied by various authors. Present study shows that accused was close friend of the victim in $47 \%$ of the cases; while he was completely stranger in $5 \%$ of the cases. While findings of Indian studies were similar with close friend of the victim being offender in $37 \%(3)$ of cases to $55 \%(5)$ of cases. The reason proposed was that a closer acquaintance knows about the weakness of a victim and takes advantage of her loneliness by development of trust. ${ }^{(7)}$ However, rape cases in Indian context were found to be consensual in $62 \%$ of cases(11) Majority of such cases are of consensual elopement and sexual activity of victim and accused; however they were covered under stringent provisions of POCSO Act. ${ }^{(11)(12)}$

Consensual sexual activity is also one of the reasons for lack of genital injuries in all cases and non-genital injuries in only $5.3 \%$ cases in present study. In 5 cases (13.2\%), penis was circumcised. Presence of smegma was noted in only 1 case (2.6\%). Genital examination of the accused did not reveal any evidence of sexual assault. The findings of our study are consistent with the study done by Veeresh. ${ }^{(6)}$

National Crime Record Bureau plans to compile 'Sex Offenders Database at National Level' with primary goal to provide tracking and monitoring of the offenders. ${ }^{(2)}$ More studies with background of present study will provide a holistic view of sexual offenders. However, this study had several limitations which included absence of data regarding offenders of sexual assault where victims were male. Psychiatric evaluation of the offenders was not evaluated as plea was not raised regarding it. Less sample size may have less statistical impact of the results, but might reflect the burden of the evil in the society and provide comparative data and impetus for further studies involving larger population strata.

\section{Conclusions}

It is a known fact that recorded rape cases are only the tip of the iceberg as not only many cases of rape are not reported, but also many of those cases in our country are not registered. The forensic examination of the victim as well as accused may play a vital role in helping the law to give justice to the victims. The present study shows that young adult males were involved in majority of cases. 
This denotes the immature mind set of young adults who are more prone to commit an offence. We encounter two types of offence one being the genuine rape cases and another type is in which the girls had gone voluntarily with their boyfriends. In such cases, the minor age of girls makes the accused as culprit and punishable for their offence. To prevent such kind of cases there should be a proper education for both teenage girls and boys. Further, consensual sexual activity between teenagers can be decriminalized to avoid criminal stigma.

\section{Conflicts of Interest: Nil}

\section{Source of Funding: Nil}

Ethical Clearance: Obtained from the Institutional Ethics Committee.

\section{References}

1. World Health Organization. Sexual violence [Internet]. Global Campaign for Violence Prevention. [cited 2019 May 11]. p. 149. Available from: https://www.who.int/violence_injury_ prevention/violence/global_campaign/en/chap6. pdf

2. Kumar I, Panwar S, Saxena SK, Raj R. National database of sexual offenders. NCRB J. 2018;1(1):37-43.

3. Kaushik N, Pal SK, Sharma A, Thakur GC. A retrospective study of sexual assaults in southern range of Himachal Pradesh. Int J Heal Sci Res. 2016;6(2):342-51.

4. National Crime Record Bureau. Crimes in India 2016 [Internet]. [cited 2019 May 10]. Available from: http://ncrb.gov.in/
5. Bhowmik K, Chaliha R. A descriptive one year study on the alleged male and female victims and accused of sex crimes. J Indian Acad Forensic Med. 2011;33(3):214-20.

6. Veeresh MR , Chidananda PS. Three-year retrospective study of forensic and psychosocial aspects in alleged assailants of sexual offences. Indian Journal of Forensic Medicine and Pathology. 2011; 4(3): 125-130.

7. Sahu G, Mohanty S, Dash JK. Vulnerable victims of sexual assault. Med Sci Law. 2005; 45(3): 25660.

8. McDermott S, McBride B, Gorman M, Sexual assault statistics from the Republic of Ireland for 2004-2005. Med Sci Law 2008; 48(2):142-147.

9. Roychaudhury UB, Bose TK, Prasad R. Rape : Its medicolegal and social aspect. J Indian Acad Forensic Med 2008;30(2): 69-71.

10. Al-Azad MAS, Rahman Z, Ahmad M, Wahab MA, Ali M , Khalil MI. Socio demographic characteristics of alleged sexual assault (rape) cases in Dhaka city. JAFMC 2011; 7(2): 21-24.

11. Sujatha PL, Ananda K, Sane MR. Profile of victims of natural sexual offences in South Bangalore. J Indian Acad Forensic Med. 2016;38(3):274-7.

12. Tailor C, Govekar G, Patel G, Sylajiya D. The profile of age in cases of victims of sexual offence. J Indian Acad Forensic Med 2010;32(4): 303-307. 